artigo ] volume 10 | NúMERO 21 | MAIO 2017

[TAINÁ MACEDO VASCONCELOS]

Mestre em Artes Cênicas pela UFPB; professora assistente da Licenciatura em Teatro da Universidade Federal do Amapá.

E-mail: taina@unifap.br

\title{
0 traje de cena na sala de aula
}

\section{Costume design in the classroom}

[resumo] Este trabalho tem como objetivo indicar aspectos relacionados à criação de trajes de cena na escola, contribuindo para a potencialização do ensino de teatro, bem como apresentar uma proposta de laboratório em que o aluno possa compreender as etapas de elaboração e confecção de figurinos. Nessa perspectiva, o projeto Laboratório de Criação de Figurinos: Experiência e Formação Artística na Educação Básica como Prática Extensionista é citado como exemplo.

\section{[palavras-chave}

\section{figurino; teatro; ensino.}

[abstract] This paper aims to discuss issues related to costume design in school, contributing to the quality increase of theatre education in school and propose a laboratory, where the student can understand the steps of making costumes. In this perspective, the project Laboratory of costume design: Experience and artistic training in high school as extension practice is an example.

[keywords] Costume design; theatre; education. 


\section{Introdução}

0 traje de cena é a indumentária utilizada nas artes cênicas, no teatro, na dança, no circo, nas performances (VIANA; PEREIRA, 2015). Tudo o que veste 0 ator, o bailarino, o performer, o artista cênico pode ser considerado traje de cena.

Por muito tempo, utilizou-se o termo figurino como sinônimo de traje de cena e ainda hoje isso acontece, como se pode observar no Dicionário de teatro, de Patrice Pavis. Para ele, o figurino é parte integrante da encenação como significante cênico (PAVIS, 1999). 0 figurinista é capaz de compor a cena com informações sobre as personagens e o contexto em que estão inseridas. A escolha do figurinista influencia na percepção do espectador, por isso, a necessidade de definir cores, volumes e texturas adequadamente para cada espetáculo.

0 processo de criação do traje de cena abrange as seguintes etapas: análise do texto ou tema para criação individualizada; estudo de referências estéticas e históricas; criação dos croquis com indicação dos materiais e das cores; confecção dos trajes de cena, provas e manutenção após a entrega. Esse percurso pode acontecer de variados modos nas produções profissionais de teatro (MUNIZ, 2004) e também na escola.

\section{Arte, teatro e traje de cena na escola}

A arte deveria ser considerada essencial para a formação do sujeito, pois, por meio da experiência estética, o indivíduo torna-se capaz de observar o mundo de forma consciente e crítica. Por muito tempo, a prática artística abordada nas instituições educativas tinha caráter formador de artistas virtuosos. Hoje, a maior luta é fazer com que a arte esteja presente em todos os niveis de ensino da educação básica, do infantil ao médio, e em todas as suas expressões.

Para a educadora Ana Mae Barbosa, o ensino de arte na escola deve compreender uma abordagem triangular que envolve o conhecimento prático da criação artística, a visão do espectador que aprecia a arte e a noção histórica da arte. "O conhecimento em artes se dá na intersecção da experimentação, da decodificação e da informação. (...) 0 que a arte na escola principalmente pretende é formar o conhecedor, fruidor, decodificador da obra de arte" (BARBOSA, 1994, p. 32). 0 ensino do teatro, assim como o ensino das artes, deve incluir estes três aspectos: do saber, do fazer e do ler o objeto ou a ação artística. Ao estudar a história da arte, 0 aluno compreende o primeiro elo desse tripé. Ao praticar a criação artística, alcança-se o segundo, e o terceiro elo vem dos momentos de apreciação em que o aluno assiste a um espetáculo ou visita uma mostra de artes visuais, sendo capaz de assimilar o que viu.

Ao estudar arte na escola, a criança desenvolve o olhar estético sobre o mundo, potencializa a consciência crítica e atinge um desempenho cognitivo mais eficaz, além de alcançar a autonomia.

0 intercruzamento de padrões estéticos e o discernimento de valores devia ser o princípio dialético a presidir os conteúdos dos currículos na escola, através da magia do fazer, da leitura desse fazer e dos fazeres de artistas populares e eruditos, e da contextualização destes artistas no seu tempo e no seu espaço. (BARBOSA, 1994, p. 34)

Ao sugerir que o currículo escolar esteja embasado na formação ética e artística do sujeito, a autora propõe que a escola se aproxime da comunidade, buscando aprender com aqueles que já produzem arte. Dessa forma, o repertório artístico da criança é intensificado tanto pela cultura popular como pela erudita visto que tal ação, somada à compreensão e ao fazer prático da arte, resulta na aprendizagem e na construção de indivíduos críticos e sensíveis. 
Segundo a Lei de Diretrizes e Bases da Educação Nacional 9.394/1996, o ensino fundamental "tem como objetivo a formação básica do cidadão, mediante (...) a compreensão das artes", e no ensino médio há apenas um destaque para as artes. Isso indica que, segundo a LDBEN, o ensino de arte acontecerá de forma genérica.

Em 1998, foram publicados os Parâmetros Curriculares Nacionais (PCNs) para o ensino de artes no ensino fundamental. Esse documento apresenta as diretrizes curriculares para o ensino de arte, dividido em quatro linguagens: artes visuais, dança, música e teatro. Todavia, fica a critério da escola definir qual linguagem artística irá abordar e de que forma - se será anual ou bimestral, por exemplo. Para cada linguagem artística são definidos os objetivos gerais, os conteúdos e os critérios de avaliação.

Em 2016, foi aprovado o Projeto de Lei que altera a LDBEN de 1996, compreendendo que o ensino de teatro é componente curricular obrigatório em todas as etapas e modalidades da educação básica. E institui o prazo de cinco anos para a implantação das mudanças, incluindo a formação de novos professores na área. Porém, ainda hoje, o espaço destinado às artes na escola confunde-se com atividades de recreação e decoração, vinculadas a datas festivas do calendário. A esperança é de que, com toda a legislação a favor, o ensino de teatro ganhe força e alcance todos os niveis da educação básica como componente curricular.

Fundamentado nos PCNs, o ensino do teatro tem como conteúdo conhecer os elementos essenciais para a elaboração de um espetáculo teatral, bem como experimentar, pesquisar e criar maquiagens, máscaras, cenários e figurinos, além de suscitar a utilização de materiais disponíveis na comunidade e na escola, com o objetivo de experimentar os elementos da linguagem teatral. Com base nisso, é possivel afirmar que os elementos teatrais compõem o ensino do teatro, o traje de cena, que devem ser encarados como possibilidades de construções pedagógicas para os alunos.

Portanto, o que se propõe com este trabalho é retomar as ideias presentes nos PCNs, em que o estudo dos elementos teatrais é fundamental para a formação do alunado. Com isso, o traje de cena passa a ser visto como conteúdo capaz de proporcionar experiências significativas no processo de formação dos sujeitos. Com a efetivação de uma sala de elaboração, confecção e acervo de trajes, a escola está permitindo 0 acesso às fases de criação do espetáculo teatral, bem como contribuindo para a formação de futuros artistas.

\section{A criação de trajes de cena na escola}

A criação de figurinos na escola acontece sempre que um espetáculo é desenvolvido por professores, monitores e alunos. 0 traje de cena pode assumir 0 papel mais importante nas montagens, devido à precariedade técnica e à falta de tempo para realizar um bom trabalho, assim como pode causar vários problemas, pois a falta de organização pode acarretar em atrasos na entrega dos trajes e 0 resultado esperado pode não ser alcançado. A confecção dos trajes se dá com a contratação de profissionais externos, e os pais dos alunos costumam financiar as roupas. Na maioria das vezes, esse processo externo foge do alcance dos professores e monitores.

0 que mais ocorre nas escolas é a precariedade relacionada ao ensino das artes. Não existe espaço adequado para a prática artística. Ao falarmos de teatro, o espaço mínimo exigido é uma sala com chão limpo, mas nem isso é liberado pela direção escolar, fazendo com que os professores improvisem.

Há, no entanto, algumas exceções. Como exemplo, é possivel citar o trabalho desenvolvido em 2008 pelo projeto Arte Educação, da Fundação Jaime Câmara, de Goiânia (G0), com o apoio das secretarias de educação e da arquidiocese local. Esse projeto foi uma iniciativa de complementação do ensino formal, oferecido 
pela $0 N G$, por meio de oficinas que envolviam artes, esportes e conteúdos gerais. No fim do ano letivo, houve a apresentação de um espetáculo teatral que relacionou as atividades das oficinas ofertadas.

A professora Kelly Bianca Clifford Valença (2010) relatou a sua experiência nesse processo. A primeira falha indicada por Valença foi a falta de preparo dos professores sobre assuntos técnicos específicos da arte. Ao ficar responsável pelo desenvolvimento da cenografia e dos figurinos do espetáculo final, relatou que foi preciso estudar e fazer oficinas que introduzissem o assunto aos professores envolvidos, haja vista que esses profissionais não possuiam formação em cenografia, matéria não abordada na licenciatura de artes visuais, na sua formação de origem. 0 trabalho foi desenvolvido em três meses, de outubro a dezembro, e resultou em mais de 300 trajes de cena, incluindo adereços.

0 processo de criação desses trajes foi descrito nas seguintes etapas:

Etapa I: Medição corporal de todos os alunos do projeto.

Etapa II: Organização das tabelas de medidas referentes aos alunos de cada cena teatral.

Etapa III: Concepção dos modelos e elaboração dos desenhos da indumentária de cada cena.

Etapa IV: Seleção e compra dos tecidos, aviamentos e acessórios necessários à confecção do figurino.

Etapa V: Entrega dos desenhos, tabela de medidas, tecidos e aviamentos à costureira encarregada.

Etapa VI: Supervisão da costura.

Etapa VII: Conferência do número de roupas, bem como das medidas, após a entrega.

Etapa VIII: Organização e etiquetagem dos cabides em araras (divisão por cenas).

Etapa IX: Realização de acabamentos, apliques e/ou pequenas costuras necessárias à finalização de alguns trajes.

Etapa X: Confecção de acessórios não encontrados para venda ou aluguel em Goiânia, a exemplo de arranjos de cabelo, chapéus com design específico, etc.

Etapa XI: Providência dos sapatos e acessórios de todos os personagens.

Etapa XII: Organização dos sapatos (por numeração) e acessórios dos personagens principais.

Etapa XIII: Suporte às crianças - nos camarins - em dias de espetáculo. (VALENÇA, 2010, p. 249)

Com esse relato é possivel perceber, no processo de criação de trajes de cena em um ambiente escolar, algumas características específicas, como a elaboração dos modelos ou croquis, a confecção, a distribuição e organização dos figurinos para apresentação. Os croquis podem ser realizados pela professora ou pelos alunos como uma atividade pedagógica. A confecção é feita por uma costureira contratada, em alguns casos, envolvendo a comunidade, podendo ser familiar de algum aluno e integrar o projeto como parceira. 0 processo de distribuição dos trajes de cena deve ser muito cuidadoso - quando houver mais de um modelo igual, é importante etiquetá-lo de maneira visivel. A organização do camarim, ou da sala onde ficam guardados as roupas e os adereços, é fundamental para não ocasionar perdas nem furtos. Nesse contexto, não há nenhuma preocupação com a conservação desses trajes de cena.

A respeito de outro aspecto da criação de trajes de cena na escola, é possivel redimensionar essa noção partindo da análise contextualizada da minha própria 
experiência como figurinista, na montagem do texto Maria Roupa de Palha, de Maria de Lourdes Nunes Ramalho, no Instituto Paraibano de Ensino Integrado (Ipei). A montagem fez parte do evento pedagógico chamado Caminho das Artes e se desenvolveu no ano de 2010. Esse projeto visava integrar todos os alunos do ensino fundamental II na montagem de um espetáculo teatral.

Os alunos se dividiram por todas as etapas de criação de um espetáculo cênico. Alguns grupos foram se destacando. Aqueles que tocavam algum instrumento ou cantavam se reuniram para desenvolver a trilha sonora. Outros se disponibilizaram como atores. Alguns desejavam ajudar, mas não queriam aparecer em cena, e se tornaram contrarregras e assistentes. Pais e amigos também foram convidados a contribuir de alguma forma com o trabalho.

Para enriquecer o espetáculo, a coordenação da escola e a professora de artes investiram em oficinas formadoras para os alunos, tais como sobre adaptação do texto teatral, sonoplastia, iluminação e traje de cena.

0 processo criativo dos trajes cênicos surgiu dessa oficina. Cada turma ficou responsável pelos personagens que eles representavam e, após debate sobre os trajes, os alunos desenhavam ou escreviam as suas ideias. 0 fato de haver opiniões divergentes sobre determinado figurino poderia tornar heterogêneo o resultado $e_{\text {, }}$ por isso, a presença do profissional da área foi fundamental a fim de direcionar o trabalho dos alunos para o melhor caminho.

A importância desse trabalho se dá pelo fato de indicar o processo colaborativo ${ }^{1}$ como estímulo para inclusão de alunos na aprendizagem do fazer teatral, além de desmistificar a produção de um espetáculo teatral para os alunos por meio do ponto de vista de um profissional da área, neste caso, meu ponto de vista como figurinista.

Entre todos os trajes de cena, gostaria de citar o da turma do 70 ano, responsável pelo figurino dos personagens Peixes. A indicação para esses personagens era simples: 0 traje deveria se assemelhar às roupas de pescadores. Os desenhos foram bem interessantes, mas a maioria apresentou a mesma estrutura: calça curta, camiseta simples, chinelo, chapéu e vara de pescar. As cores mais usadas foram o azul e o amarelo, e a escolha aconteceu de maneira intuitiva, sem requerer nenhum estudo prévio.

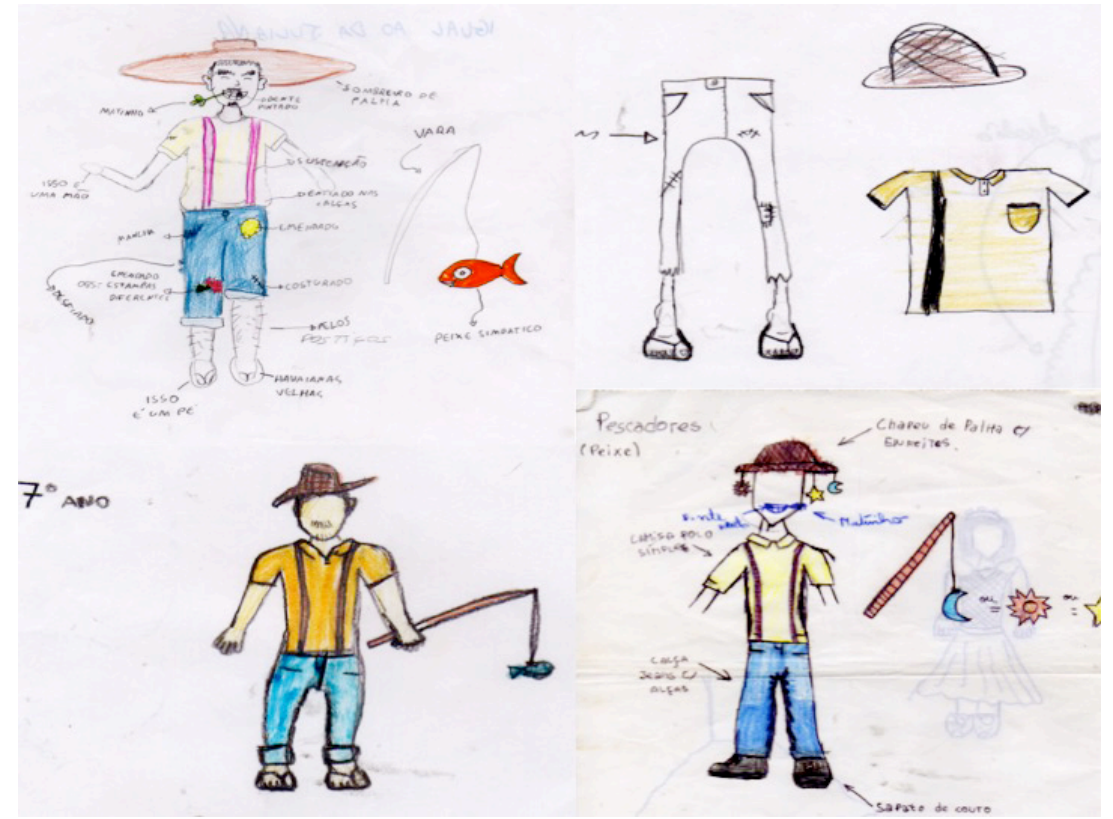

Figura 1 - Desenhos dos alunos para os personagens Peixes. Fonte: Acervo cedido à figurinista. 


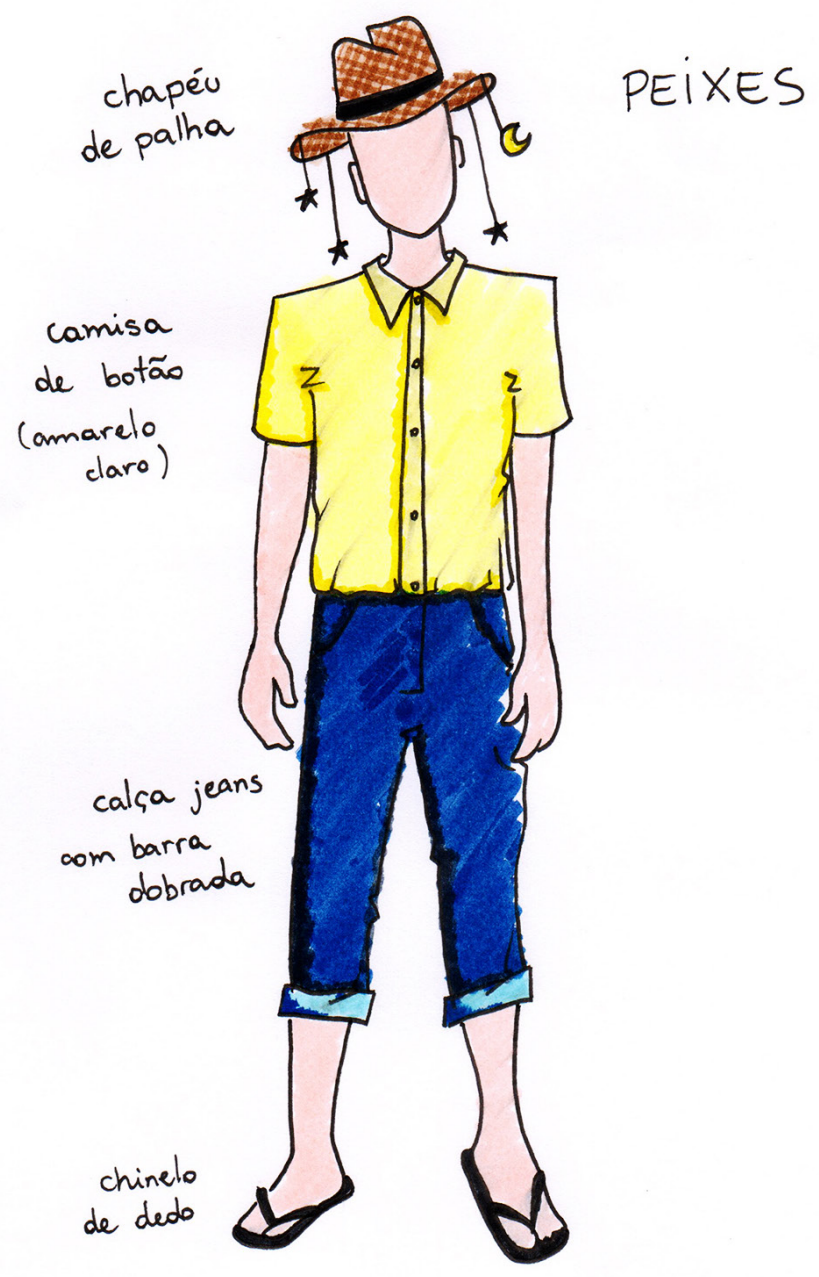

Figura 2 - Desenho para os personagens Peixes. Fonte: Croqui final da figurinista.

Esse croqui foi enviado aos responsáveis pelos alunos para que encaminhassem à costureira de sua preferência. 0 processo de não utilizar o serviço de costura de uma mesma pessoa, ainda que com o desenho e com uma cartinha explicativa, gera trajes de cena diferentes. Nesse caso, apesar das diferenças, houve, de algum modo, uma unidade no conjunto visual ainda mais interessante. Em vez de todos os atores exibirem o mesmo modelo de roupa, como um fardamento, os trajes se diferenciavam em comprimento e tonalidades de cores, porém, aproximavam-se da questão do conceito estabelecido para a personagem. 0 traje de cena, mesmo confeccionado com tecidos diferentes, cumpria o padrão que havia sido estabelecido pelos alunos no desenho, e isso foi mantido até o fim.

A montagem do espetáculo Maria Roupa de Palha contribuiu para a integração dos alunos com a criação artística. 0 projeto Caminho das Artes acontece até hoje no Ipei e continua possibilitando aos alunos o contato com o fazer teatral.

De maneira geral, observa-se que pouco se fala sobre o modo de criação de trajes de cena na escola. 0 relato da professora Valença (2010) deixa claro as inúmeras lacunas que existem no processo de ensino e aprendizagem do teatro, desde a formação do professor nas licenciaturas até o espaço que é disponibilizado pelas escolas para realização de atividades artísticas.

0 processo criativo de trajes cênicos na escola pode ocorrer de diversas formas. Os exemplos citados aqui partem do conhecimento empírico e são assumidos enquanto objetos de estudo. É possível criar os croquis a partir do texto, sem a interferência dos alunos, fazendo uma elaboração maior das características dos personagens, ou incluir os alunos nesse processo, de forma que cada um sinta-se 
responsável por uma parcela do trabalho. A confecção pode ficar a cargo de uma costureira contratada, que realizará o projeto igualmente para todos os participantes, ou dividida entre várias costureiras de acordo com o desejo dos responsáveis pelos alunos.

Entretanto, observa-se que o trabalho cresce positivamente ao envolver a comunidade no processo criativo. 0 professor de artes, ao criar os figurinos sem 0 auxílio dos alunos, pode privar a estes a oportunidade de experimentar esse processo. Quando vivencia o fazer criativo, o aluno é capaz de refletir sobre os personagens e suas histórias e desenvolver os trajes de cena. Em vez de contratar uma costureira alheia ao processo, pode-se convidar uma profissional que trabalhe na comunidade ao redor da escola, que pode ser a mãe de algum aluno ou não. Ao compreender a importância desse evento para o desenvolvimento do aluno enquanto cidadão do mundo, contribui-se para a formação de um indivíduo sensivel e criativo, atendendo, dessa forma, aos Parâmetros Curriculares Nacionais sobre $o$ ensino de artes.

\section{Laboratório de criação de trajes de cena}

0 laboratório de criação de figurinos é uma proposta de ateliê criativo, que visa alcançar a prática de elaboração e confecção de trajes cênicos como conhecimento necessário à experimentação do que é teatro, a ser desenvolvida em escolas, universidades, associações, sedes de grupos artísticos e outras instituições. Esse espaço deve ser destinado a estudantes, pesquisadores, artistas e pessoas interessadas em participar do processo de concepção de figurinos. Com isso, os alunos poderão compreender o aspecto de produção que ocorre antes do espetáculo, para que este se concretize visualmente, e também contribuir para a formação de novos figurinistas.

Essa proposta torna-se viável a partir do momento em que a produção teatral é recorrente no âmbito educativo. Ao identificar a falta de condições mínimas na maioria dos espaços educativos, esse laboratório pode ser viabilizado de acordo com as necessidades de cada comunidade, bairro e cidade, em que um mesmo laboratório pode servir a diferentes escolas, basta organizar os horários e a agenda. Com a implementação do laboratório de criação de figurinos, o fazer teatral na escola irá alcançar outro patamar ao integrar o aluno como sujeito criativo e responsável pela sua produção.

Para efetivação, basta que uma ou mais instituições consintam, trabalhando para a escolha do ambiente adequado, para o financiamento dos equipamentos e móveis e divulgação das atividades oferecidas. Os custos são de responsabilidade das instituições realizadoras do laboratório e podem ser financiados pela iniciativa pública ou privada, a critério de cada instituição.

0 laboratório de criação de figurinos é organizado por áreas divididas da seguinte forma: criação, confecção, beneficiamento e acervo. Ao levar em consideração o processo de planejamento e a confecção de uma peça de roupa, não se pode deixar de tomar como exemplo o ateliê de moda. Sue Jenkyn Jones (2005) apresenta as principais caracteristicas de um ateliê de moda para uma faculdade.

0 ateliê de uma faculdade pode ser organizado de várias formas. Pode simular o estúdio de um estilista ou o ambiente de uma pequena fábrica, dependendo da estrutura do curso e do equilíbrio entre o número de estudantes, professores e assistentes da área técnica. Algumas faculdades permitem que cada aluno tenha sua própria estação de trabalho e outras oferecem um ambiente sem divisões, onde os estudantes usam os equipamentos por ordem de chegada. (JONES, 2005, p. 138) 
Sobre o espaço físico, a melhor opção é a estruturação de um ambiente comunitário, sem estações individuais de trabalho, com o intuito de favorecer a colaboração e a construção do saber coletivo. Em primeiro lugar, a sala deve ser ampla e bem ventilada, a instalação elétrica deve ter sido revisada de acordo com as normas de segurança da companhia elétrica local e contar com um balcão com torneira fixa.

A criação de figurinos sempre passa por uma etapa inicial de elaboração e planejamento, que se denomina criação. A maior parte dos processos criativos exige algo relacionado à costura, como a confecção de uma peça inteira, ou à remodelagem; para essa atividade, foi pensado o segundo espaço, a confecção. 0 terceiro espaço, chamado beneficiamento, está voltado aos processos de acabamento e customização, necessários a todos os modos de criar figurinos. 0 quarto e último espaço é o acervo, parte fundamental do processo, pois é nesse lugar que serão armazenadas as matérias para criação, confecção e customização dos figurinos, além de guardar as roupas que forem produzidas na instituição.

\section{Como aplicar no espaço educativo?}

Será apresentada aqui uma proposta de aplicação do laboratório de criação de figurinos em um espaço educativo, que pode e deve ser alterada de acordo com as possibilidades de cada instituição. Essa é apenas uma indicação a partir do que foi discutido no decorrer deste texto, uma alternativa para execução desse laboratório.

A escolha deu-se por uma sala com dimensões que atingem $8 \times 8 \mathrm{~m}$, dividida em quatro áreas. A referência para visualização é uma pessoa em pé na porta, olhando para dentro do laboratório. Do lado esquerdo da porta fica a área de criação, com uma bancada para seis pessoas e um quadro branco na parede. No centro da sala, está localizada a mesa de modelagem e corte, destinada a dez pessoas. No fim do lado esquerdo, estão as máquinas de costura, até então, quatro máquinas (duas retas e duas overloque). No fim da sala, por trás da mesa de modelagem e corte, estão o balcão com torneira, espaço para um varal, fogão com uma boca e uma mesa para bordados e aplicações finais. Por último, no lado direito da porta, estão dois armários para guardar os materiais necessários à criação e confecção de figurinos, além de uma arara para pendurar os figurinos prontos, e um provador no canto da sala.

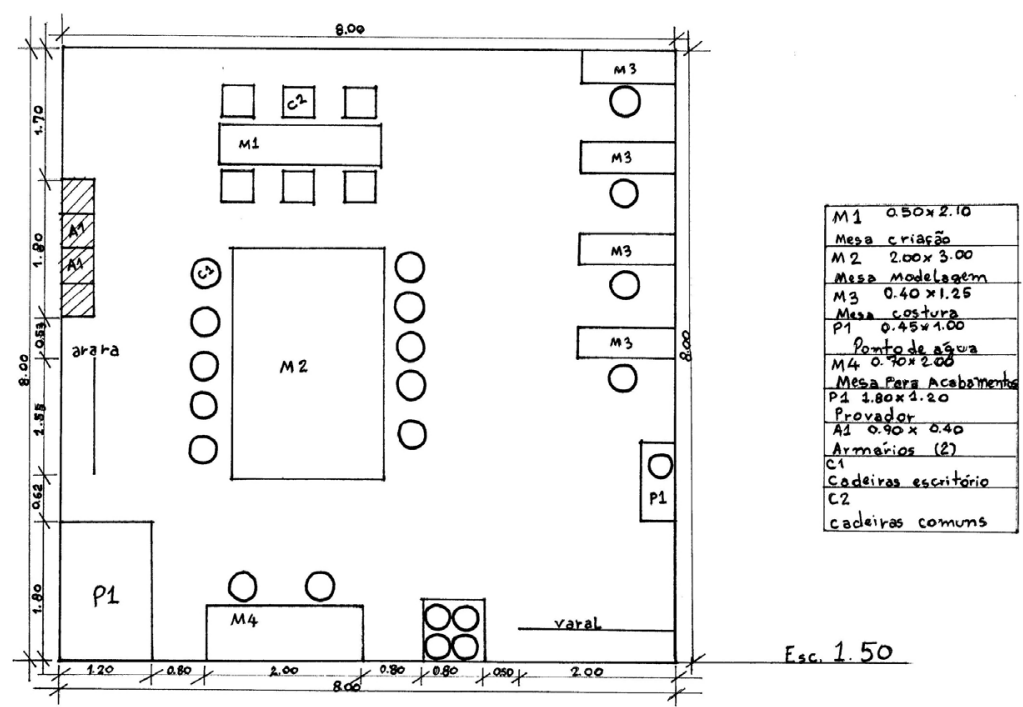

Figura 3 - Esboço do laboratório de criação de figurinos, em sala com proporção de 8 × 8 m. Fonte: Croqui elaborado por Rafael Uchoa. 
Ao todo, segundo essa possibilidade, o laboratório poderá receber cerca de 25 pessoas, por isso é necessário organizar uma escala de uso, levando em consideração a demanda existente. É importante que cada laboratório estabeleça os horários de funcionamento e as regras de utilização.

\section{Projeto-piloto}

Para efetivação dessa proposta, estou realizando, desde junho de 2016, 0 projeto de extensão Laboratório de Criação de Figurinos: Experiência e Formação Artística na Educação Básica como Prática Extensionista, na Universidade Federal do Amapá em parceria com a Escola Estadual Maria Ivone de Menezes, na cidade de Macapá (AP). Sabe-se que a prática extensionista deve promover a integração do universo acadêmico com a sociedade. Com base nessa relação, entre universidade e ambiente escolar, é que esse projeto tem se desenvolvido, buscando levar o teatro como área de conhecimento para todos.

A escolha por trabalhar com uma escola de ensino fundamental e médio se deu pela necessidade de acordar a juventude para a criatividade artística. Além de auxiliar o amadurecimento do aluno enquanto sujeito crítico e sensivel, o projeto colabora para a formação inicial como figurinista, estando apto a trabalhar com os grupos artísticos do Estado do Amapá.

A realização desse projeto vem somar qualidade ao ensino de teatro e à experiência artística do aluno, de maneira que, ao se envolver com o processo de construção do espetáculo cênico, por meio da elaboração dos trajes de cena, 0 aluno estará ampliando suas capacidades cognitivas com a atividade criativa. Por outro lado, está fortalecendo uma área técnica dentro das artes cênicas que possui poucos profissionais (principalmente no Amapá), e, a partir desse projeto, podem surgir novos figurinistas.

No Estado do Amapá há a necessidade de formação de figurinistas. As produções artísticas locais carecem de profissionais preparados para criar e confeccionar trajes de cena de acordo com as especificidades de cada espetáculo. Na maioria das vezes, o próprio ator, bailarino ou intérprete é responsável por elaborar 0 seu traje, prejudicando a unidade visual do espetáculo.

A partir da experiência com a criação e a confecção de figurinos, o intuito é servir a comunidade com uma experiência significativa em teatro, que resulte em novas produções artísticas no âmbito dos trajes cênicos. Ao longo de um ano letivo, participarão desse projeto 20 alunos do ensino médio (maiores de 15 anos) e dez pessoas da comunidade em geral.

Com o aumento do número de vagas, a comunidade em geral, e principalmente a classe de artistas de Macapá, está sendo beneficiada com a execução desse projeto. Aqueles que até então trabalhavam como autodidatas, agora podem discutir, compartilhar e aprender técnicas diferentes de criação de figurinos.

A parceria com a escola é fundamental para a execução do projeto, pois os encontros semanais acontecem nela, às segundas e sextas-feiras às $18 \mathrm{~h} 30$. Para não prejudicar as atividades regulares dos alunos, os encontros são no turno da noite, privilegiando também os interessados da comunidade que possuem atividades durante o dia. As reuniões acontecem em uma sala ampla com carteiras e equipamento para projeção de imagens. Ainda não é possível dispor de equipamentos de costura, mas está sendo discutida junto à Pró-Reitoria de Extensão da Unifap a aquisição de máquinas de costura para esse projeto, favorecendo a vivência prática das etapas do processo criativo de trajes de cena.

0 projeto é dividido em quatro etapas, das quais a primeira já foi realizada. Cada uma aborda um aspecto do processo criativo de trajes cênicos. A primeira etapa aconteceu no período de 26 de agosto a 6 de setembro de 2016 e foi dedicada a uma introdução conceitual sobre traje de cena com uma abordagem lúdica que envolvesse os participantes. As discussões partiram do que é figurino, traje de 
cena, indumentária... As artes cênicas foram exploradas em quatro expressões: teatro, dança, circo e performance. A partir do que foi refletido nos encontros e baseado no conto Chapeuzinho Vermelho, os participantes criaram livremente, por meio do desenho e da colagem, possibilidades de trajes de cena para a protagonista, nas diferentes expressões artísticas estudadas e, assim, finalizamos a primeira etapa.

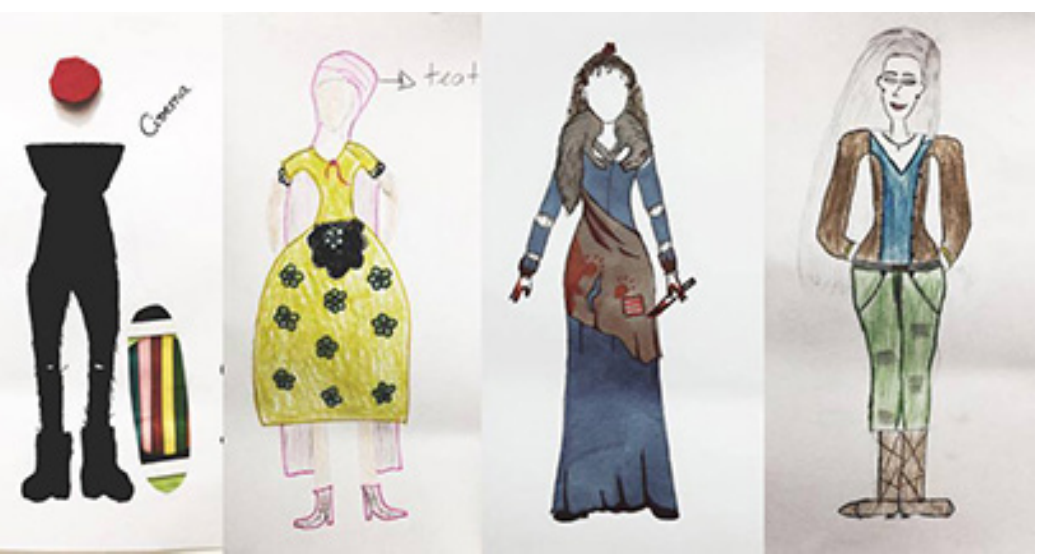

Figura 4 - Criação livre do traje de cena de Chapeuzinho Vermelho pelos participantes da primeira etapa do projeto Laboratório de Criação de Figurinos, na Escola Estadual Maria Ivone de Menezes, Macapá (AP). Fonte: Acervo dos alunos.

A segunda etapa terá início no fim de outubro e duração de um mês, assim como as etapas seguintes. Para dar continuidade às atividades, iremos estudar diferentes processos criativos de trajes de cena com base na leitura do trabalho do figurinista Paulo Vinícius (2010). Serão avaliados processos em reconstrução histórica, criação livre, composição a partir de roupas que já existem, processo colaborativo e estimulação do espetáculo a partir do figurino. Também são objetivos dessa etapa estudar técnicas de desenho para trajes de cena e elaborar painéis imagéticos de referências para a criação de trajes.

A terceira e a quarta etapas se complementam, pois, nesse momento, os participantes iniciarão (na terceira etapa) e finalizarão (na quarta) um projeto de traje cênico a partir de um texto dramatúrgico escolhido em sala de aula. Essa atividade deverá envolver todos os personagens do referido texto.

Como resultado, serão apresentados os trajes de cena criados pelos alunos e as demonstrações dos processos criativos. Com a finalização do projeto, novas turmas surgirão e o contato com outras escolas também, ficando o professor de artes responsável por manter e utilizar as atividades do laboratório de criação de figurinos na sua escola.

Também será elaborado um material didático de apoio sobre trajes de cena a partir da prática na sala de aula, com a participação de outros professores do colegiado de teatro da Unifap. A cada renovação do projeto, espera-se montar um acervo de material didático sobre criação de trajes cênicos, visto que a publicação desse material servirá para incentivar a prática teatral em outras escolas.

\section{Considerações finais}

0 traje de cena é componente integrante no fazer teatral. Além de contribuir para a construção da visualidade do espetáculo, pode indicar características dos personagens representados, facilitando o entendimento do espetáculo como um todo por parte do espectador. 
Ao vislumbrar o ensino de teatro atualmente, percebo que poucas são as opções metodológicas utilizadas pela maioria dos professores e os conteúdos não ultrapassam muito os jogos teatrais. Até porque a estrutura fisica disponivel para as aulas de artes não se apresenta adequada para o trabalho criativo e cênico.

Com isso, a criação desse laboratório vem somar qualidade ao ensino de teatro e experiência artística ao aluno. Por outro lado, estaremos fortalecendo qualitativamente uma área técnica dentro das artes cênicas que possui poucos profissionais, além do que, a partir dessa experiência, podem surgir novos figurinistas.

Essa proposição pode soar utópica, partindo do pressuposto que as atuais condições do ensino das artes no Brasil estão se desenvolvendo em passos lentos. Porém, esse é um olhar inicial, uma proposta de base, que pode alavancar outras experiências criativas e artísticas para a sociedade.

A experiência com o projeto de extensão da Universidade Federal do Amapá ainda é pequena para uma análise profunda, porém, é perceptível o interesse da escola, do professor de arte, dos alunos e de artistas locais em participar de uma iniciativa como essa. 0 Estado do Amapá carece de profissionais ligados à parte técnica teatral, que envolve os figurinistas. Esse projeto tem demonstrado uma nova possibilidade para experimentação artística dos participantes. Porém, a efetivação do laboratório, de acordo com a proposta colocada, está muito à frente das condições necessárias para a sua realização, pois ainda não temos maquinário para costura, nem mesas adequadas para desenho e corte de tecidos. Mas acredito na possibilidade de firmar parcerias mais sólidas, com a Unifap e a Secretaria de Educação do Estado, a fim de proporcionar experiências significativas nesse processo compartilhado de aprendizagem.

Para o pedagogo Célestin Freinet, "a escola nunca é uma parada. É a estrada aberta para os horizontes que se devem conquistar" (FREINET, 2004, p. 34). Essa experiência pedagógica é mais importante se for observada com foco no horizonte a ser conquistado - a formação artística e estética dos alunos e participantes envolvidos.

A pretensão deste trabalho sempre foi alcançar, de forma criativa, um novo aspecto do ensino de teatro e valorizar a aprendizagem de várias etapas da prática artística, contribuindo para a formação de sujeitos críticos e artistas autônomos. Compreendendo as dificuldades no tocante à infraestrutura necessária para realizar ações teatrais dentro e fora da escola, a intenção é ultrapassar as barreiras com criatividade e ação.

Recebido em: 02/01/2017

Aprovado em: 07/02/2017 


\section{NOTAS}

10 processo colaborativo nas artes cênicas está associado ao envolvimento de diferentes profissionais (encenador, ator, cenógrafo, iluminador, figurinista etc.) no compartilhamento de ideias sobre o mesmo projeto.

\section{REFERÊNCIAS}

BARBOSA, Ana Mae. A imagem no ensino de arte. 2. ed. São Paulo: Perspectiva, 1994.

BRASIL Secretaria de Educação Fundamental. Parâmetros Curriculares Nacionais: Arte / Secretaria de Educação Fundamental. Brasília: MEC/SEF, 1997. 130p. Disponível em: <http://portal.mec.gov.br/seb/ arquivos/pdf/livro06.pdf>. Acesso em: 5 mar. 2016.

BRASIL Lei de Diretrizes e Bases da Educação Nacional. Lei no 9.394, de 20 de dezembro de 1996 Disponivel em: < http://www.planalto.gov.br/ccivil_03/leis/L9394.htm>. Acesso em: 5 mar. 2016.

FREINET, Célestin. A pedagogia do bom senso. São Paulo: Martins Fontes, 2004.

JONES, Sue Jenkyn. Fashion design: manual do estilista. São Paulo: Cosac Naify, 2005.

MUNIZ, Rosane. Vestindo os nus: figurino em cena. Rio de Janeiro: SENAC, 2004.

PAVIS, Patrice. Dicionário de teatro. São Paulo: Perspectiva, 1999.

VALENÇA, Kelly Bianca Clifford. Produção de figurino X formação docente continuada: desafios de uma experiência com alunos da educação básica. In: Revista Polyphonía, Goiás, vol. 21, n.1, pp. 243-253, jan. jun. 2010. Disponivel em: <http://www.revistas.ufg.br/index.php/sv/article/view/16311/9942>. Acesso em 29 nov. 2014.

VIANA, Fausto; PEREIRA, Dalmir Rogério. Figurino e cenografia para iniciantes. São Paulo: Estação das Letras e Cores, 2015.

VINÍCIUS, Paulo. 0 figurino no teatro contemporâneo. Curitiba: 2010. Disponivel em: $<$ http:// teatrofigurinoecena.blogspot.com.br/2010/06/o-figurino-no-teatro- contemporâneo.html>. Acesso em: 3 out. 2015. 